\title{
Testis Tümörü Erken Tanısında Kendi Kendine Muayenenin Yeri: Dünyada ve Türkiye'de Durum
}

\section{The Status of Testicular Self-Examination in the Early Diagnosis of Testicular Cancer: Conjuncture in the World and in Turkey}

\author{
Dr. Barış Kuzgunbay \\ Başkent Üniversitesi Tıp Fakültesi, Üroloji Anabilim Dalı, Adana, Türkiye
}

\begin{abstract}
Özet
Testis kanseri nadir görülmesine rağmen, 15-35 yaş arasında en sık görülen kanser olması nedeni ile önemli bir halk sağlığı problemidir. Kendi kendine testis muayenesi (KKTM) ise testisteki fiziksel anormalliklerin erken fark edilmesini sağlayan, uygulanması son derece basit bir yöntemdir. Erken tanı ile testis kanseri daha erken evrede tespit edilebilmekte, bu sayede uygulanacak tedavi daha az toksik ve daha basit olmaktadır. Bununla beraber, literatürdeki epidemiyolojik çalışmalar, dünyada ve ülkemizde toplumun testis kanseri ve KKTM ile ilgili bilgisinin kısıtlı olduğunu göstermektedir. Bu nedenle birçok gelişmiş ülkede testis kanserinin farkındalığını arttırmak ve KKTM teşvik etmek amacıyla çeşitli halk sağlığı kampanyaları düzenlenmektedir. (Üroonkoloji Bülteni 2014;13:127-129)
\end{abstract}

Anahtar Kelimeler: Testis kanseri, erken tanı, kendi kendine testis muayenesi

\begin{abstract}
Summary
Testicular cancer, although rarely seen, is considered to be an important public health problem since it is the mostly seen cancer in the males between the ages of 15-35. Testicular self-examination (TSE) is the easiest way to detect the physical abnormalities of the testicles earlier. Testicular cancer is detected at the earlier stage with the earlier diagnosis, thus it is likely to be associated with more simple and less toxic treatment. However, the epidemiological studies in literature describe limited awareness of men about testicular cancer and TSE in the world and in our country. Thus, various public health campaigns have been arranged in order to increase the public awareness of testicular cancer and encourage the TSE in most of the developed countries. (Bulletin of Urooncology 2014;13:127-129)
\end{abstract}

Key Words: Testicular cancer, early diagnosis, testicular self-examination

anında dikkatli evreleme, erken dönemde uygun tedavi yaklaşımı (cerrahi, kemoterapi, radyoterapi), çok yakın takip ve gerektiğinde kurtarma tedavileridir (1). Yapılan çalışmalarda, testis kanseri tanısı koymak ve tedaviye başlamak için ortalama gecikme sürelerinde son on yılda azalma gözlemlenmiştir (2). Kendi kendine testis muayenesi (KKTM) testisteki fiziksel anormalliklerin erken fark edilmesini sağlayan, uygulanması son derece basit bir yöntemdir. Bununla beraber, literatürdeki epidemiyolojik çalışmalar göstermiştir ki dünyada ve ülkemizde testis kanseri ve KKTM ile ilgili toplumun bilgisi ve farkındalığı kısıtlıdır (3,4,5,6,7,8,9,10), (Şekil 1).

Testis kanserinin taramasında KKTM uygulamasının yeri hala tartışma konusudur. Testis kanserinde, düzenli KKTM ile yaşam süreleri arasındaki ilişkiyi kanıtlayan çalışma olmadığından dolayı US Preventive Services Task Force ve Canadian Task Force gibi bazı kuruluşlar hastalarda yersiz endişeye ve gereksiz doktor ziyaretlerine yol açabileceğinden 


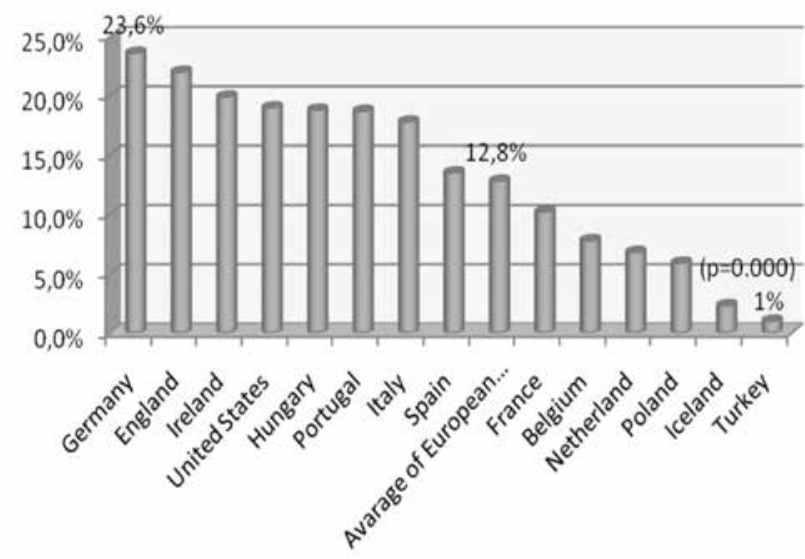

Şekil 1. Türkiye ve diğer ülkelerde kendi kendine testis muayenesi uygulama oranları

dolayı düzenli KKTM'yi önermemektedirler (11). American Medical Association (AMA) ve American Urological Association (AUA) ise testis kanserinin erken tanısı için KKTM ile ilgili halkın bilgilendirilmesi ve eğitilmesini önermektedir. Bunu da hastalığı tespit etmekte gecikme ile tanı anında klinik evre arasında anlamlı ilişki olduğunu gösteren çok sayıda çalışmanın kanıtlarına dayandırmaktadırlar $(3,4,5,6,7)$. İleri evre testis kanserlerinde dahi kemoterapi ve radyoretapi ile başarılı tedavi sonuçları bildirilse de erken tanı ile tespit edilen erken evre testis kanserinde tedavi daha az toksik ve daha basit olmaktadır. European Association of Urology (EAU) ise tarama programlarının avantajlarını kanıtlayan çalışmalar olmamasına rağmen evre ve prognozun direk olarak erken tanı ile ilgili olduğunun gösterilmesinden dolayı klinik risk faktörleri olan erkeklerde KKTM'yi önerilebilir bulmaktadır (1).

Ingiltere'de 2002 yılında yapılan epidemiyolojik çalışmada testis kanseri ile ilgili farkındalık oranının \%91 ve düzenli KKTM uygulama oranının \%22 olduğu bulunmuştur. Yazarlar, erkek sağlığı kliniklerinin ve halk sağlığı kampanyalarının toplumun bilinçlendirilmesinde etkili olabileceğini bildirmişlerdir (3). Bunun üzerine İngiltere'de son 10 yılda testis kanseri konusunda toplumun bilincinin arttırılmasına önem verilmiştir. Bu amaçla bilgi içeren el broşürleri dağıtılmış, halk üzerinde etkisi olabilecek popüler kişiler (örnek; şarkıcı Robbie Williams) üzerinden medya kampanyaları düzenlenmiş, Londra maratonunda reklamları yapılmış ve TV'de KKTM pratik olarak gösterilmiştir.

Amerika Birleşik Devletleri'nde yapılan çalışmalarda, testis kanseri ile ilgili farkındalık oranının \%30-\%86 ve düzenli KKTM uygulama oranının \%2-\%19 olduğu bulunmuştur. 2000 yılında, MTV'nin sıradışı kişiliği ve komedyeni Tom Green, testis kanseri tanısı alarak orşiyektomi ve retroperitoneal lenf nodu disseksiyonu ile tedavi edilmiştir. Daha sonra toplumu testis kanseri konusunda haberdar etmek ve erkekleri KKTM konusunda teşvik etmek amacıyla Tom Green operasyonun sınırlı bir kısmını MTV'de izleyicilerin gösterimine sunmuştur. European Health Behavior Study (EHBS), 21 Avrupa ülkesinde 16,486 üniversite öğrencisi üzerinde yaptığı anket çalışmasında,
KKTM yapma oranı ortalama \%12,8 (İzlanda \%2,3 ve Almanya $\% 23,6$ ) olarak bulmuştur $(8)$.

Nijerya'da, 2011 yılında 750 katılımc ile yapılan araştırmada testis kanserinden haberdar olma oranı \%10,4, düzenli kendi kendine muayene yapma oranı ise \%1 olarak bulunmuştur (12). Yazarlar, bilgi düzeyinin arttırılması ve KKTM yapılmasının teşvik edilmesi için ülkede sağlık kampanyaları düzenlenmesini ve sağlık kliniklerine herhangi bir sebepten gelen genç erkeklere sağlıkçılar tarafından bilgilendirilme yapılmasını önermişlerdir.

Türkiye'de Üroonkoloji Derneği bünyesinde, 12 ayrı merkezde 799 üniversite öğrencileri üzerinde yapılan anket çalışmasında, ülkemizde testis kanserinin varlığından haberi olanların oranı $\% 11,1$, testis kanseri ve KKTM ile ilgili doğru bilgi sahibi olma oranı \%1,4 ve düzenli KKTM yapma oranı \%1 olarak bulunmuştur (10). Katılımcıların testis kanseri ile ilgili bilgileri medya ve internet $(\% 67,1)$, okul $(\% 5,6)$, arkadaş $(\% 11,2)$ ve tıbbi kaynaklar $(\% 11,2)$ yoluyla edindiği bildirilmiştir. Daha sonra Ankara'da 634 üniversite öğrencisinin katılımı ile yapılan bir anket çalışmasında düzenli KKTM yapma oranı \%2,5 olarak bulunmuştur (13). Yine ülkemizde 275 üniversite öğrencisinin katılımı ile yapılan diğer bir anket çalışmasında düzenli KKTM yapma oranı \%4,3 olarak rapor edilmiştir (14). Bu çalışmaların sonuçlarına göre ülkemiz diğer Avrupa ülkelerinin ve Amerika Birleşik Devletleri'nin oldukça gerisinde kalmaktadır. Bu verilerden yola çıkarak Üroonkoloji Derneği, ülkemizde toplumu testis kanseri ile ilgili bilgilendirmek ve KKTM uygulama yönünde teşvik etmek gerekliliği üzerinde görüş bildirmiştir. Bu amaçla dernek web sayfasına testis kanseri ve ile ilgili açıklayıcı bir yazı ve KKTM ile ilgili bilgilendirici bir görsel konulmuştur. Ayrıca dernek imkanları doğrultusunda medya ve televizyon kampanyalarının yapılması planlanmaktadır.

Sonuç olarak, yapılan çalışmalar göstermiştir ki ülkemizde ve dünyada testis kanseri ve KKTM ile ilgili bilgiler ve uygulamalar istenilen seviyenin altındadır. Bu nedenle, ülkeler sağlık politikalarının elverdiği ölçüde halkın bilgi düzeyini arttırmak amaçlı projeler uygulamaktadırlar. Ülkemizde de yapılacak kapsamlı uygulamalarla, toplumun testis kanseri ve KKTM konusunda hızlı bir şekilde bilinçlenmesi ihtiyaç göstermektedir.

Çıkar çatışması: Yazarlar bu makale ile ilgili olarak herhangi bir çıkar çatışması bildirmemişlerdir.

\section{Kaynaklar}

1. Albers P, Albrecht W, Algaba F, et al. Guidelines on testicular cancer. EAU 2014;1:1-54.

2. Wanderas EH, Tretli S, Fossa SD. Trends in incidence of testicular cancer in Norway 1955-1992. Eur J Cancer 1995;31:2044-2048.

3. Khadra A, Oakeshott P. Pilot study of testicular cancer awareness and testicular self examination in men attending two South London general practices. Family Practice 2002;19:294-296.

4. Blesch KS. Health Beliefs about testicular cancer and self-examination among professional men. Oncon Nurs Forum 1986;13:29-33.

5. Katz RC, Meyers K, Walls J. Cancer awareness and self-examination practices in young men and women. J Behav Med 1995;18:377-384.

6. Brenner JS, Hergenroeder AC, Kozinetz CA, Kelder SH. Teaching testicular self-examination: Education and pratices in pediatric residents. Pediatrics 2003;111:239-244. 
7. Singer AJ, Tichler T, Orvieto R, et al. Testicular carcinoma: a study of knowledge, awareness, and practice of testicular self-examination in male soldiers and military physicians. Millitary Medicine 1993; 158:640-643.

8. Wardle I, Steptoe A, Burckhardt R, et al. Testicular self-examination: Attitudes and practices among young men in Europe. Prev Med 1994;23:206-210.

9. Casey RG, Grainger R, Butler MR, et al. Public awareness of testis cancer and the prevalence of testicular self-examination-changing patterns over 20 years. Urology 2010;76:915-918.

10. Kuzgunbay B, Yaycioglu O, Soyupak B, et al. Public awareness of testicular cancer and self-examination in Turkey: a multicenter study of Turkish Urooncology Society. Urol Oncol 2013;31:386-391.

11. Westlake SJ, Frank JW. Testicular self-examination: An argument against routine teaching. Fam Pract 1987;4:143-148.

12. Ugboma HA, Aburoma HL. Public awareness of testicular cancer and testicular self-examination in academic environments: a lost opportunity. Clinics (Sao Paulo) 2011;66:1125-1128.

13. Ugurlu Z, Akkuzu G, Karahan A, et al. Testicular cancer awareness and testicular self-examination among university students. Asian Pac J Cancer Prev 2011;12:695-698.

14. Özbaş A, Çavdar I, Findik ÜY, Akyüz N. Inadequate knowledge levels of Turkish male university students about testicularself-examination. Asian Pac J Cancer Prev 2011;12:919-922. 